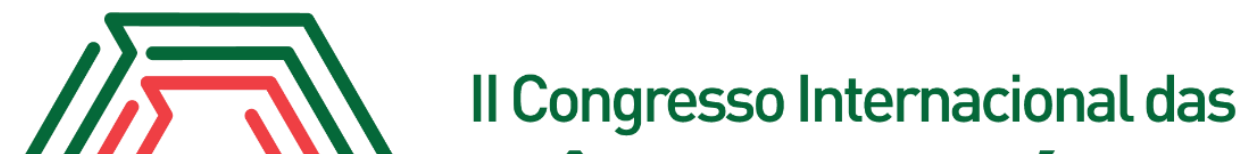 Ciências Agrárias COINTER - PDVAgro 2017
}

\section{AVALIAÇÃO DA CTC E SATURAÇÃO POR BASES EM DIFERENTES SISTEMAS DE PRODUÇÃO EM UM LATOSSOLO AMARELO}

\author{
Apresentação: Pôster \\ Kleve Freddy Ferreira Canteral ${ }^{1}$; Manuella Almeida Raiol da Silva ${ }^{2}$; Letícia Coelho Vaz \\ Silva $^{3}$; Jôsi Mylena de Brito Santos ${ }^{4}$; Mário Lopes da Silva Júnior ${ }^{5}$
}

\section{Introdução}

A qualidade do solo se baseia na manutenção do equilíbrio ambiental, sustentando a produtividade biológica do sistema, assim auxiliando na promoção do bem estar da comunidade biótica inerente ao ecossistema (ARAGÃO et al., 2012). Entretanto, para efetuar essa avaliação de maneira eficaz é necessário entender a dinâmica entre o solo e seus atributos, que são modificados em função do manejo ou ainda por fatores externos (CARNEIRO et al., 2008).

Estudos sobre a qualidade dos atributos corroboram para melhor entender a dinâmica destes com o solo, visto que o adequado crescimento e desenvolvimento das plantas e organismos dependem, dentre outros fatores, da qualidade conferida pelos atributos do solo, assim contribuindo para a manutenção da diversidade ecológica nesses sistemas (SILVA et al., 2003).

Os atributos químicos, físicos e biológicos se inter-relacionam no solo e o seu reflexo está intimamente associado a qualidade do solo e, consequentemente, à cultura empregada, podendo ocasionar problemas vinculados à produtividade, quando encontram-se em condições desfavoráveis à planta (SILVA et al., 2003).

A hipótese desenvolvida neste estudo foi embasada na influência que diferentes sistemas de produção: pastagem, plantio de milho e plantio de açaí, aliados a profundidades de 0-20 cm e 20-40 $\mathrm{cm}$ conferem a algumas propriedades químicas do solo, como a CTC efetiva, CTC pH 7,0 e

\footnotetext{
${ }^{1}$ Engenharia Ambiental e Energias Renováveis, Universidade Federal Rural da Amazônia, canteralkleve@gmail.com; manuellaalmeida39@gmail.com; leticiacvaz@gmail.com; josimbsantos@gmail.com

2 Engenheiro Agrônomo, Dr. e Professor do Instituo de Ciências Agrárias da UFRA, Universidade Federal Rural da Amazônia, mario.silva@ufra.edu.br
} 
saturação por bases (V\%) e se essas variáveis se correlacionam.

Neste contexto, o presente trabalho objetivou avaliar a resposta de alguns atributos químicos, como a CTC efetiva, CTC pH 7 e V\% em função de dois diferentes sistemas de produção: pastagem e cultivo agrícola, além de verificar se nesses sistemas existe correlação entre estes atributos químicos.

\section{Fundamentação Teórica}

O gerenciamento agrícola é um dos princípios da agricultura de precisão, que parte de informações de solo e de culturas (AMADO \& SANTI, 2007). Assim, torna-se imprescindível o conhecimento acerca da variabilidade dos atributos do solo e de cultura, pois configuram um importante mecanismo no que se refere à investigação do melhor rendimento observado pela cultura de interesse, assim aumentando o manejo em áreas agrícolas (CARNEIRO et al., 2008).

Os diferentes sistemas de manejo acarretam alterações nos atributos físicos, biológicos e químicos do solo, a exemplo da matéria orgânica, que pode influenciar diretamente na CTC de solos com argila de baixa atividade (CIOTTA et al., 2003).

O milho (Zea mays L.) é cultivado em vários lugares do mundo e os resíduos deixados no solo são relevantes para o incremento de carbono no solo. O açaizeiro (Euterpe oleracea Mart.) possui uma distribuição preponderantemente tropical e subtropical, sendo encontrados geralmente em áreas de várzea (ANDREOTTI et al., 2000).

\section{Metodologia}

A área de estudo localiza-se na Fazenda Bela Vista, situada na região sul do município de Abaetetuba - PA (154'30,64', S 48 53'18,54', O). O clima local, segundo a classificação de Köppen, é do tipo Am, super úmido. A topografia do terreno apresenta-se relativamente plana e o solo é classificado como Latossolo amarelo distrófico com textura média. Os sistemas de produção avaliados foram: pastagem, milho e açaí, sendo que o delineamento experimental foi inteiramente casualizado, em esquema fatorial 3 x 2, com quatro repetições, totalizando 24 parcelas amostrais.

A amostragem do solo foi realizada em maio de 2017, para os três tipos de sistemas de produção supracitados. Com o auxílio do trado sonda e o trado holandês, foram coletadas 15 
amostras simples, nas profundidades de 0-20 cm e 20-40 cm, para formar uma amostra composta, sendo estas colocadas em um recipiente limpo, onde ocorreu a homogeneização das mesmas. Após, as amostras foram enviadas para o laboratório de química do solo da Universidade Federal Rural da Amazônia, as quais foram secadas ao ar (TFSA), destorroadas, passadas em peneira com diâmetro de $2 \mathrm{~mm}$ e homogeneizadas, e posteriormente foram realizadas as análises químicas.

Utilizou-se o software ArcGIS 10.5.1, no laboratório de geoprocessamento da Universidade Estadual do Pará - UEPA, a fim de melhor ilustrar o percentual de saturação por bases nas profundidades de 0-20 e 20-40 cm nos diferentes sistemas descritos. A técnica de interpolação adotada foi o inverso do quadrado da distância, pois a técnica de krigagem não mostrou dependência espacial, não sendo, portanto, adequada para os dados em questão. Além deste, fez-se uso de um outro programa computacional, AGROSTAT 1.1.0.702, no qual os dados foram processados e submetidos ao teste de Tukey a 5\% de probabilidade, para comparar as médias e obter a correlação entre as variáveis mencionadas.

\section{Resultados e Discussões}

Os resultados obtidos para a CTC efetiva apontam que houve significância a 1\% de probabilidade pelo teste de Tukey, conforme demonstra a tabela 1.

Tabela 1: Análise de variância para efeitos principais e interação entre a CTC efetiva, CTC pH 7,0 e saturação por bases (V\%). Fonte: Própria

\begin{tabular}{|c|c|c|c|c|c|c|}
\hline Parâmetro & $\begin{array}{l}\text { Causas de } \\
\text { Variação }\end{array}$ & GL & SQ & $\mathbf{Q M}$ & $\mathbf{F}$ & $\mathbf{P}$ \\
\hline \multirow{3}{*}{ CTC efetiva } & Efeito Fator A & 2 & 1,8394333333 & 0,9197166667 & $28,61 * *$ & $<0,00015$ \\
\hline & Efeito Fator B & $\mathbf{1}$ & 0,6800666667 & 0,6800666667 & $21,15^{* *}$ & 0,000218 \\
\hline & $\begin{array}{c}\text { Efeito Interação } \\
\text { AxB }\end{array}$ & 2 & 0,1780333333 & 0,0890166667 & $2,77 \mathrm{~ns}$ & 0,0894 \\
\hline \multirow{4}{*}{ СТC pH 7,0 } & $\begin{array}{l}\text { Causas de } \\
\text { Variação }\end{array}$ & GL & SQ & $\mathbf{Q M}$ & $\mathbf{F}$ & $\mathbf{P}$ \\
\hline & Efeito Fator A & 2 & 4,1427750000 & 2,0713875000 & $15,92 * *$ & 0,0001 \\
\hline & Efeito Fator B & 1 & 0,0486000000 & 0,0486000000 & $0,37 \mathrm{~ns}$ & 0,5487 \\
\hline & $\begin{array}{c}\text { Efeito Interação } \\
\text { AxB }\end{array}$ & 2 & 6,1242750000 & 3,0621375000 & $23,53 * *$ & $<0,0001$ \\
\hline \multirow{4}{*}{$\mathrm{V} \%$} & $\begin{array}{l}\text { Causas de } \\
\text { Variação }\end{array}$ & GL & SQ & $\mathbf{Q M}$ & $\mathbf{F}$ & $\mathbf{P}$ \\
\hline & Efeito Fator A & 2 & 34,327508333 & 17,163754167 & $15,94 * *$ & 0,0001 \\
\hline & Efeito Fator B & 1 & 259,51526667 & 259,51526667 & $240,96 * *$ & $<0,0001$ \\
\hline & $\begin{array}{c}\text { Efeito Interação } \\
\text { AxB }\end{array}$ & 2 & 105,79915833 & 52,899579167 & $49,12 * *$ & $<0,0001$ \\
\hline
\end{tabular}


Observa-se que CTC efetiva apresentou valores significativos quando analisadas separadamente, ou seja, esta variável é afetada de acordo com a cultura empregada e ainda pela profundidade, o que está em conformidade com estudos realizados por Ciotta et al. (2003), onde discorrem que a CTC tende a diminuir de acordo com a profundidade, isto ocorre sobretudo quando os solos não são naturalmente férteis e os teores de CTC são explicados devido ao aporte de matéria orgânica pincipalmente nas camadas superficiais, a exemplo das regiões de clima tropical, onde há predominância de solos com argila de baixa atividade. No entanto, quando associadas não demonstram correlação, isto é, as variáveis não dependem umas das outras para serem explicadas.

A tabela 1 afirma que a CTC pH 7,0 varia de acordo com o tipo de cultura utilizada, contudo a profundidade não exerce influência sobre esta variável. Falleiro et al. (2003) obteve resultados semelhantes a estes, pois a CTC pH 7 não foi afetada pela profundidade em diferentes sistemas, como a semeadura direta. Verifica-se que há uma correlação entre os dois fatores sobre a variável analisada.

A saturação por bases (V\%) teve significância para os três efeitos, ou seja, o tipo de cultura e a profundidade explicam a variável em questão, além dos fatores se correlacionarem entre si, como disposto na tabela 1 .

Os percentuais de saturação por bases na profundidade de $0-20 \mathrm{~cm}$ apresentaram valores médios de $18,26 \%$ e reduziram na profundidade de $20-40 \mathrm{~cm}$, apresentando resultados médios de $11,68 \%$, como ilustrado no mapa 1 , situado a seguir.

Figura 1: Distribuição dos teores de saturação por bases na profundidade de $0-20 \mathrm{~cm}$ e $20-40 \mathrm{~cm}$, respectivamente, na Fazenda Bela Vista. Fonte: Própria
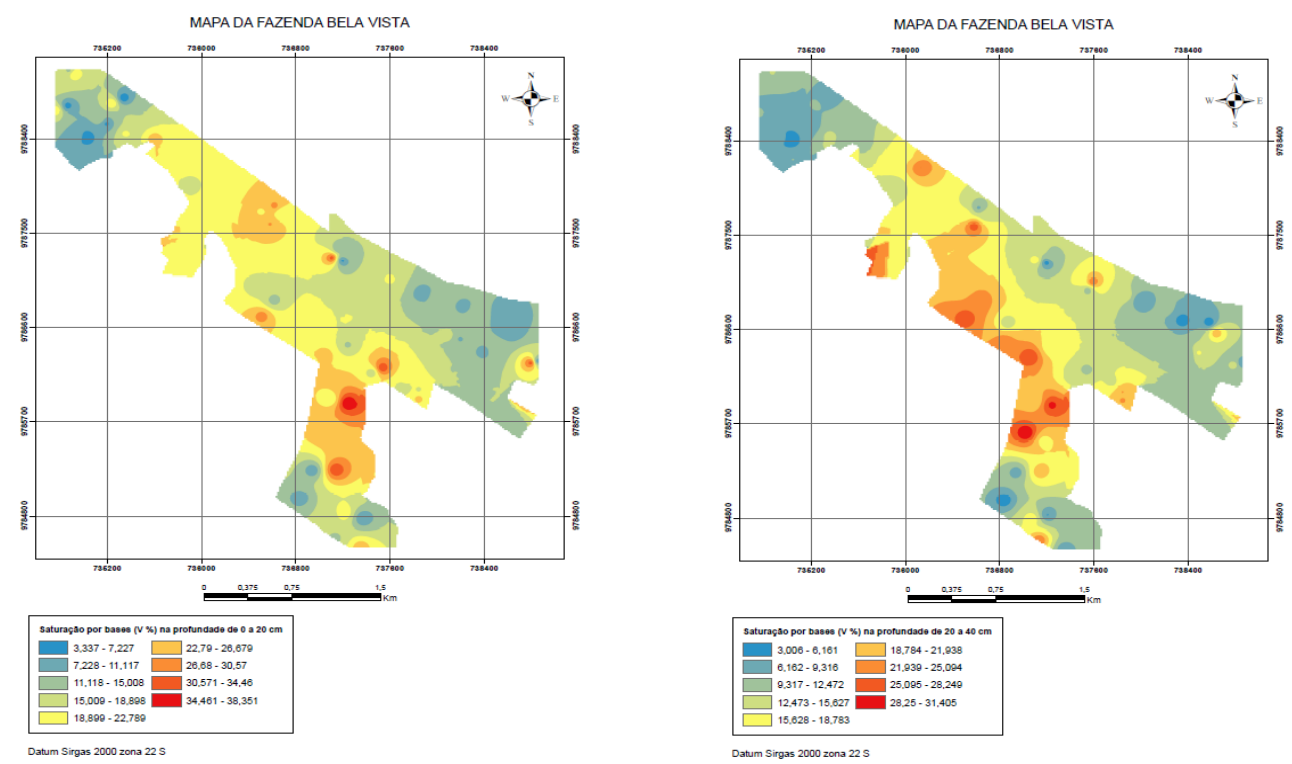
A tabela 3 salienta que não houve efeito significativo entre a CTC efetiva e CTC pH 7,0, isto é, não houve uma dependência ou diferenciação entre as variáveis supracitadas. Em contrapartida, a saturação por bases (V\%) foi afetada pela CTC efetiva e pela CTC pH 7,0.

Tabela 3. Análise de correlação entre as variáveis. Fonte: Própria

\begin{tabular}{ccc}
\hline & CTC efetiva & CTC pH 7,0 \\
\hline CTC pH 7,0 & 0,34469 ns & - \\
& 0,0991 & - \\
\hline V\% & $0,53304^{* *}$ & $-0,41358^{*}$ \\
& 0,0073 & 0,0445 \\
\hline
\end{tabular}

\footnotetext{
** significativo ao nível de $1 \%$ de probabilidade $(\mathrm{p}<.01)$. $*$ significativo ao nível de $5 \%$ de probabilidade $(.01=<\mathrm{p}$ $<.05)$. ns: não significativo ao nível de $5 \%$ de probabilidade.
}

\section{Conclusões}

Observa-se que os objetivos propostos foram atendidos, pois, estatisticamente o tipo de cultura e as profundidades $0-20 \mathrm{~cm}$ e $20-40 \mathrm{~cm}$ afetam a CTC e a saturação por bases. A CTC efetiva e CTC pH 7,0 não apresentaram correlação, porém, para a saturação por bases ocorreu o efeito oposto, indicando que a CTC, seja ela efetiva ou pH 7,0, influencia em seus resultados.

\section{Referências}

AMADO, T.J.C. \& SANTI, A.L. Agricultura de precisão aplicada ao aprimoramento do manejo do solo. In: FIORIN, J.E., ed. Manejo da fertilidade do solo no sistema plantio direto. Passo Fundo, Berthier, 2007. p. 99-144

ANDREOTTI, Marcelo et al. Produção de matéria seca e absorção de nutrientes pelo milho em razão da saturação por bases e da adubação potássica. Pesquisa Agropecuária Brasileira, v.35, n.12, p. 2437-2446, 2000.

ARAGÃO, Débora Veiga de et al. Avaliação de indicadores de qualidade do solo sob alternativas de recuperação do solo no Nordeste Paraense. Acta Amazônica, v. 42, n. 1, p. 11-18, 2011.

CARBONE CARNEIRO, Marco Aurélio et al. Atributos físicos, químicos e biológicos de solo de cerrado sob diferentes sistemas de uso e manejo. Revista Brasileira de Ciência do Solo, v. 33, n. 1, p. 147-157, 2009.

CIOTTA, Marlise Nara et al. Matéria orgânica e aumento da capacidade de troca de cátions em solo com argila de atividade baixa sob plantio direto. Ciência Rural. Santa Maria. Vol. 33, n. 6, p. 1161-1164, 2003.

FALLEIRO, R. M. et al. Influência dos sistemas de preparo nas propriedades químicas e físicas do solo. Revista Brasileira de Ciência do Solo, v. 27, n. 6, p. 1097-1104, 2003.

SILVA, V. R. et al. Variabilidade espacial das características químicas do solo e produtividade de milho em um Argissolo Vermelho-Amarelo distrófico arênico. Revista Brasileira de Ciência do Solo, v. 27, n. 6, p. 1013-1020, 2003. 